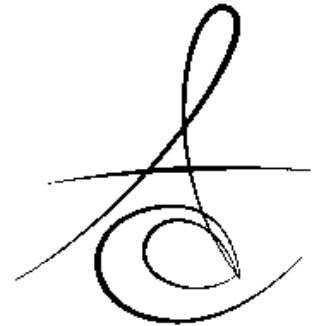

Makale Kodu/Article code: 1407

Makale Gönderilme tarihi: 21.11.2013

Kabul Tarihi: 28.01.2014

\section{LÜKSASYON YARALANMALARINDA GEÇİCİ APİKAL YIKIM}

TRANSIENT APICAL BREAKDOWN AFTER LUXATION INJURIES

\author{
Dt. Yelda KASIMOĞLU*
}

Doç. Dr. Elif Bahar TUNA-İNCE*

\section{ÖZET}

Geçici apikal yıkım (TAB) lüksasyon yaralanmalarından sonra hasar gören dokularda spontan iyileşme ile pulpada kalıc bir hasar meydana gelmemesi ile sonuçlanan bir durumdur. Yanlış yorumlandığında gereksiz endodontik tedavilerin yapılmasına neden olabilmektedir. Minimal invaziv tedavi yöntemlerinin öneminin arttığı günümüzde TAB takibi, travma gören dişlerde farklı ve koruyucu bir tedavi yaklaşımı olarak değerlendirilmektedir. $\mathrm{Bu}$ derlemenin amacl TAB etyolojisi ve patolojisini tanımlamaktır.

Anahtar kelimeler: Diş pulpası kalsifikasyonu, endodonti, kök rezorpsiyonu

\section{ABSTRACT}

Transient apical breakdown (TAB) is a sequelae of luxation injuries where the injured tissues undergo a spontaneous process of repair with no permanent damage to the pulp. Misdiagnosis of this condition may result in unnecessary endodontic treatment. The purpose of this review was to describe the etiology and pathogenesis of TAB.

Key words: dental pulp calcification, endodontics, root resorption

\section{GİRİS}

Travmatik diş yaralanmaları, tüm kafa-yüz travmaları arasında en sık karşılaşılan problemlerden biridir. 15 yaşın altındaki çocuklarda ağız ve yüz bölgesine gelen travma sıklığı \%50 olarak bildirilmekte, sıklıkla ön bölge dişleri etkilenmektedir. Etkilenen dokular arasında en çok diş sert dokuları, dişeti, periodontal dokular, pulpa ve alveol kemiği bulunmaktadır. ${ }^{1}$ Travma sonrası iyileşmeyi etkileyen faktörler arasında kök gelişim derecesi, periodontal dokulardaki hasarın yayılımı ve ağız kavitesinden gelen bakteriyel kontaminasyon sayılabilmektedir. Travma sonrası komplikasyonlar yaralanmadan sonraki birkaç hafta, ay, hatta birkaç yıl içinde meydana gelebilmektedir. ${ }^{2,3}$

Andreasen'e göre pulpanın iyileşmesi ile ilişkili görülebilecek durumlar arasında;
a. Pulpanın iyileşmesi,
b. Pulpa nekrozu,
c. Pulpa kanal obliterasyonu (PKO),
d. Geçici apikal yıkım (TAB) bulunmaktadır. ${ }^{4}$

\section{TANIM ve SINIFLAMA}

\section{-Geçici apikal yıkım (TAB)}

TAB ilk kez 1986 yılında Frances Andreasen tarafından "apeksi kapalı lükse dişlerde travma gören pulpanın veya pulpa ile periodonsiyumun tamir süreci ile ilişkili doğal iyileşme durumu" olarak tanımlanmıştır (Şekil 1). ${ }^{5}$

Apeksi kapalı dişlerde lüksasyon yaralanması ile ilişkili olarak pulpa nekrozu üzerine çeşitli istatistiksel çalışmalar yapılmasına rağmen ${ }^{1,4} \mathrm{TAB}$ ile ilgili az sayıda çalışma bulunmaktadır. ${ }^{6,7}$ Andreasen ve ark.'nın yaptığı çalışmada lüksasyon olgularında TAB sıklığı 637 vakada \%4.2 olarak belirtilmiştir. ${ }^{5}$ Sınırlı sayıda görülmesi, diş hekimlerinin travma görmüş apeksi kapalı dişlerde ne zaman TAB gelişimini değerlendirme sürecini belirsiz hale getirmektedir. ${ }^{8}$

\footnotetext{
* İstanbul Üniversitesi Diş hekimliği Fakültesi, Pedodonti Anabilim Dalı, İstanbul
} 

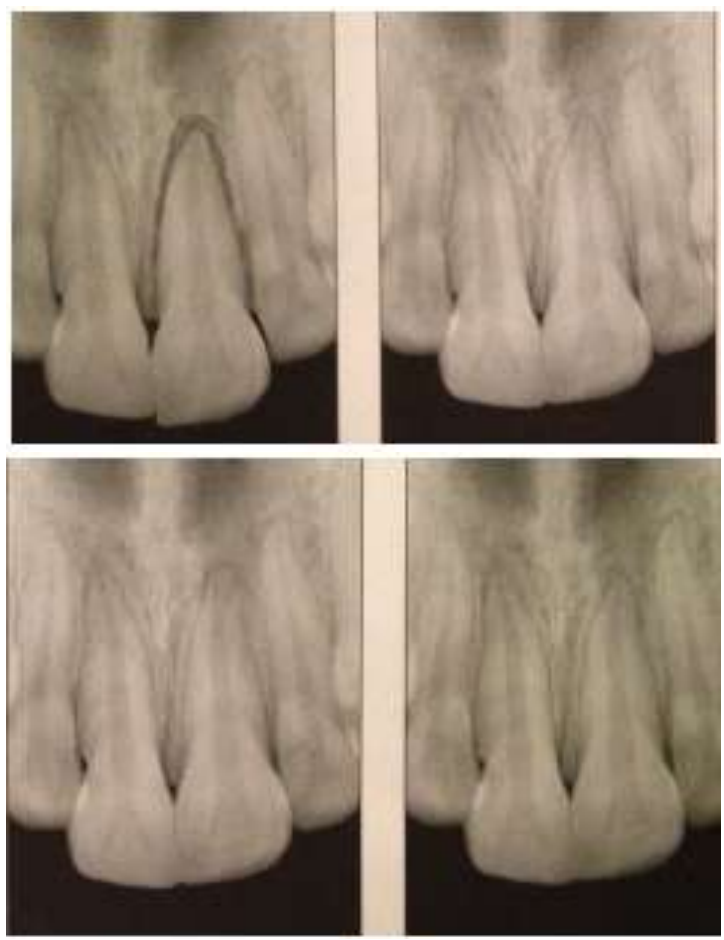

Şekil 1. Lüksasyon travması sonrası TAB. ${ }^{4}$

a. Lüksasyon travması şematize edilmiştir.

b. 21 nolu diş repoze edildikten sonra periodontal iyileşme gerçekleşmiştir.

c. Travma sonucu nörovasküler desteğin hasar gördüğü ve apikal foramenin dar olduğu dişlerde revaskülarizasyon sürecine osteoklastik aktivite eşlik ederek apikalden yeni dokuların gelişimine olanak sağlamaktadır.

d. Bu süreç geçici niteliktedir, revaskülarizasyon süreci tamamlandığında radyolusent bölge ortadan kaybolmaktadır.

\section{-Pulpa nekrozu}

Pulpa nekrozu, enfeksiyon nedeniyle pulpanın vitalitesini kaybetmesi durumudur. Travma sonucu pulpadaki kan akışı kesilebilmekte, iskemi nedeni ile pulpa nekrotik hale gelebilmektedir, bu duruma koagülasyon nekrozu adı verilmektedir. Başlangıçta enfeksiyon bulunmamakta, ancak bakteri invazyonu ile nekrotik pulpa enfekte hale gelebilmektedir. ${ }^{8}$

\section{TAB MEKANİZMASI}

Lüksasyon yaralanmaları; sarsılma, sublüksasyon, ekstrüzyon, lateral lüksasyon ve intrüzyonu içermektedir. Sarsılmanın dışındaki lüksasyon yaralanmalarında (veya kök kırıklarında kuronal parçada) avülsiyon olgularında olduğu gibi apikal kan damarlarında şiddetli hasar meydana gelmektedir.
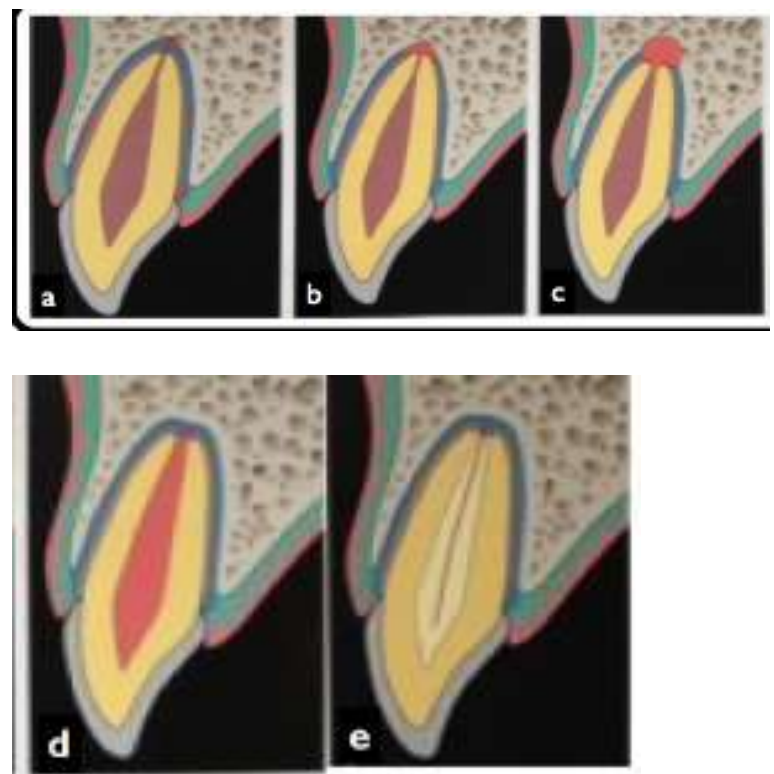

Şekil 2. TAB mekanizması. ${ }^{8}$

a. Sublüksasyon olgusu örneği verilmiştir.

b. Travmadan birkaç hafta sonra apeks çevresinde inflamatuar bir reaksiyon meydana gelmektedir.

c. Travmadan yaklaşık olarak 1-3 ay sonra osteoklast benzeri hücreler alveol kemiği, kök yüzeyi ve kökün iç duvarlarını rezorbe etmektedir.

d. Travmadan yaklaşık 3-6 ay sonra genişleyen foramen apikaleden prolifere olan kapiller damarlar pulpa boşluğuna doğru ilerlemektedir. Enflamasyon kaybolurken, yeni periodontal ligamentin yapılanmasıyla apeks tamir edilmektedir.

Klinik olgulara ve apeksi açık avülse dişlerde yapılan replantasyon çalışmalarına dayanarak, pulpanın iyileşme potansiyeli olduğu kabul görmektedir. ${ }^{9-11}$ Replantasyon sonrası kapiller kan damarları apikal foramenden ilerleyerek pulpa boşluğuna doğru kuronal yönde ilerlemekte (revaskülarizasyon), nekrotik pulpa vital doku ile yer değiştirmektedir. Vitalitesini kazanan dokularda genellikle hızlı bir kalsifikasyon meydana gelmekte, radyografik olarak pulpa kanalı obliterasyonu izlenebilmektedir. Aynı zamanda klinik olarak dişte elektriksel pulpa testine (EPT) pozitif yanıt alınmaktadır. Bu tip pulpa iyileşmesi, apikal foramen çapının $1 \mathrm{~mm}$ 'den geniş olduğu olgularda görülmektedir. Bu da apeksi kapalı dişlerde böyle bir iyileşmenin mümkün olamayacağı anlamını taşımaktadır. Ancak TAB yoluyla apikal foramen genişlediğinde, apeksi açık dişlerde olduğu gibi apeksi kapalı dişlerde de pulpa iyileşmesi meydana gelebilmektedir (Şekil 2). ${ }^{8}$

Travmadan hemen sonra apikal kan damarları

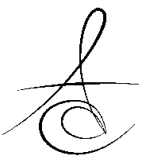


kısmen veya tamamen hasar görmekte ve pulpada iskemik değişiklikler meydana gelebilmektedir. Travmadan birkaç hafta sonra, kanamanın tetiklediği enflamatuar reaksiyon ile apekste pulpa nekrotik hale gelmektedir. Enflamatuar yanıt sürecinde ortamda osteoklastlar belirerek, apeks bölgesinde rezorpsiyona yol açmakta (radyografide kemikte radyolusens görüntü) ve travmadan sonraki yaklaşık 1 ile 3 . aylar arasında bu duruma kök rezorpsiyonu eşlik etmektedir. Kök rezorpsiyonu apeksin dış yüzeyinde ve kanal boşluğunun içinde görülmektedir.

Travmadan sonra geçen birkaç hafta ile birkaç yıl süresince rezorpsiyon nedeni ile genişleyen apeksten pulpa boşluğuna doğru kan damarlarının gelişimi mümkün hale gelmektedir. Sonraki iyileşme paterninin, replante edilen açık apeksli dişlerle benzer olduğu düşünülmektedir. Bu iyileşme sadece nekrotik pulpanın enfekte olmadığı durumlarda mümkündür. Apeks bölgesinde rezorbe olan kökün diş yüzeyi enflamasyon geçtikten sonra yeni ataçman ile tamir olmakta ve rezorbe olan kök yüzeyini sement dokusu yeniden örterek normal periodontal ligament boşluğu yapılandırımaktadır. ${ }^{1,8}$

\section{TAB İÇİN YAŞ ve TRAVMA KRİTERLERİ}

Tsukiboshi'nin kendi klinik deneyimine göre TAB, sadece 15 yaşın altındaki hastalarda görülmektedir. $^{8} \quad$ Andreasen'in 20 yaşında, ${ }^{5}$ Kobayashi'nin ise 24 yaşında TAB gelişen birer olgu raporu bulunmaktadır. ${ }^{12}$ Yaş aralığının belirsiz olması ile birlikte klinik olarak TAB'ın, 15 yaşından genç hastaların apeksi kapalı dişlerinde meydana gelebileceği bildirilmektedir. Travma tipi açısından ise TAB ile en çok sublüksasyon yaralanmalarında karşılaşılırken, ekstrüzyon ve lateral lüksasyon olgularında da TAB'a rastlanmıştır. Apeksi kapalı dişlerde avülsiyon ve intrüzyon yaralanmalarında $T A B$ beklenmemektedir. Bir diğer açıdan dişte yer değiştirme miktarı arttıkça TAB şansı azalmaktadır. ${ }^{8}$

\section{TANISI}

TAB ile PULPA NEKROZUNUN AYIRICI

Pulpal ve periapikal patolojilerin teşhisinde en sık kullanılan parametreler; perküsyon, palpasyon, mobilite, kuronda renk değişikliği, spontan ağrı, radyografik değişiklikler ve vitalite testleridir. Lüksasyon yaralanmaları ve kök kırıklarından sonra gelişen pulpa nekrozunda bahsedilen parametrelere bakıldığında dişler genellikle asemptomatik kalmaktadır. Periapikal radyolusensliğin pulpa nekrozunun en güvenilir teşhis yolu olduğu düşünülürken, yapılan çalışmalarda diagnostik açıdan geçerliliğini yitirdiği görülmektedir. Lüksasyon sonrası pulpa histolojisi, klinik ve radyografik parametreler ile karşılaştırıldığında sadece perküsyon hassasiyetinin pulpa nekrozu ile yüksek derecede ilişkili olduğu bulunmuştur. Pulpa nekrozunun üç temel belirtisi mevcut olsa da (kuronda renk değişimi, vitalite kaybı ve periapikal radyolu- senslik) ender görülmekle birlikte pulpa onarımı gerçekleşebilmektedir. ${ }^{7,13}$

Vitalite testlerinde alınan anormal yanıtlar pulpada dejeneratif değişikliklerin meydana geldiğini göstermektedir. Doğru biçimde uygulanıp yorumlandığında bu testler pulpa nekrozunu teşhis etmek için güvenilir yöntemler olarak değerlendirilmektedir. Ancak hekimler sonuçları yorumlarken hatalı pozitif ve hatalı negatif yanıtları göze almalıdırlar. Hata yapmamak için alınan negatif yanıtlarda hemen tedaviye başlanmaması önerilmektedir. ${ }^{1,7}$

TAB'ın başlangıç aşamasında kökün apikal bölgesinde ve çevreleyen kemik dokuda rezorpsiyon (radyolusenslik) görülmektedir. TAB hakkında bilgi sahibi olunmaması durumunda, bu klinik tablo pulpa nekrozu sonrası görülen patolojik radyolusenslik ile karıştırılabilmekte ${ }^{8}$ ve bu durum gereksiz endo- dontik tedavilerin yapılmasına yol açabilmektedir. ${ }^{7}$ Genellikle TAB sonucu kemikteki radyolusenslik 2. ayda başlamakta ve yaklaşık 6. ayda kaybolmaktadır. Bu dönemde kurondaki renk değişikliğinin giderek azalması TAB'ın karakteristik özelliklerinden birisidir. $\mathrm{Bu}$ nedenle TAB sonucu meydana gelen apikal radyolusenslik ile pulpa nekrozunun ayırıcı tanısının travmadan yaklaşık 6 ay sonra yapılabildiği belirtilmektedir. ${ }^{14}$

$T A B$; hastanın yaşı, lüksasyonun derecesi, ve kökün şekli gibi faktörlere bağlı olabilmekte bu nedenle bazı olgular daha uzun iyileşme süresine intiyaç duyabilmektedir. Ayrıca bazı pulpa nekrozu olgularında kuronda renk değişimi görülmezken, pulpa iyileşmesi görülen bazı olgularda da kuron renginde değişiklik görülmemektedir. Pulpa iyileşmesinin takibine EPT rehberlik etmekle birlikte bazı olgularda 2 yıl sonra EPT'ye pozitif yanıt alındığı görülmüştür. Bu nedenle birçok olguda pulpa tedavisinin gerekli olup olmadığı ve gerekirse ne zaman yapılacağı hakkında karar vermek zor bir hale gelmektedir. ${ }^{8}$ 
Yayımlanmış olan olgu raporlarından yola çıkarak TAB ile pulpa nekrozunun ayırıcı tanısı aşağıdaki biçimde yapılabilmektedir:

1. Özellikle sublüksasyon vakalarında $T A B$ gelişimi beklenmekle birlikte, hafif ekstrüzyon ve lateral lüksasyon yaralanmalarında da TAB gelişebilmektedir.

2. 15 yaşından küçük hastalarda görülebilmektedir.

3. TAB'ın amacl pulpa iyileşmesidir. Pulpa iyileşmesinin dişte EPT'ye pozitif yanıt alınması ya da radyografik olarak pulpa kanalında obliterasyon görülmesi yoluyla doğrulanması gerekmektedir.

4. TAB daha çok 6 ay içinde radyografik olarak apikal kök rezorpsiyonunun gelişmesini takiben pulpa iyileşmesinin görüldüğü durumlarda meydana gelmektedir. Bu noktada apikal kemikteki radyolusensliğin de kaybolması gerekmektedir.

5. Kuronda renk değişimi varsa, pulpanın EPT'ye yanıtı negatif ise ve travmadan sonraki 6 ay içinde TAB özellikleri görülmüyorsa pulpa nekrozu teşhisi konabilmektedir.

6. Apikal kök rezorpsiyonu oluşumundan bağımsız olarak, apikal radyolusensliğin görülmesi ve devam etmesi durumunda pulpa nekrozuna bağlı bir apikal patoloji düşünülmelidir.

7. $T A B$ ile pulpa nekrozunun ayırt edilmesi için dişin en az 6 ay süreyle takip edilmesi önerilmektedir.

8. Kuronda renk değişimi büyük ölçüde azalmış, apikal kemikteki radyolusenslik veya klinik semptomlar kaybolmuş ise bazı olgularda pulpa iyileşmesinin EPT ile tespiti 2 yıldan daha uzun sürede gerçekleşebilmektedir.

9. Kuronda şiddetli renk değişimi bulunuyorsa ve ilk 6 ay boyunca bir düzelme meydana gelmiyor ise travmadan 6 ay sonra pulpa vitalitesinden bağımsız olarak estetik nedenlerden dolayı kök kanal tedavisine başlanmalıdır. ${ }^{8}$

\section{KÖK KIRIĞI ve TAB}

Yapılan çalışmalarda kök kırıklarında pulpa sağkalımının \%60 ile \%80 arasında olduğu belirtilmiştir. ${ }^{15,-8}$ İlk radyografik belirti genellikle kaza anından 3 ay sonra görülmektedir. Bu süreçte iki parçanın ilerleyen şekilde birbirinden uzaklaştığı, sonrasında kırık hattı çevresinde periradiküler kemikte patolojik radyolusent alanlar gözlemlendiği belirtilmektedir. ${ }^{1}$

Kök kırıklarında kırık hattının çevresinde TAB görülebilmektedir. $\mathrm{Bu}$ olgularda travmanın etkisiyle pulpada şiddetli hasar görülmekte, kuronal parçada pulpa TAB mekanizması ile iyileşebilmektedir. Bu yüzden kök kırıkları da dikkatli takip edilmeli ve gereksiz kanal tedavilerinden kaçınılmalıdır. ${ }^{19}$ Yapılan araştırmalarda bu dişlerde renk değişikliği ile sık karşılaşıldığı ve bu değişimin ortadan kaybolmasının iyileşme prognozu açısından iyi bir gösterge olduğu bildirilmiştir. $^{20}$

\section{CONE BEAM BİLGİSAYARLI TOMOGRAFİ İLE TAB TAKİBİ}

Diş dokularına ait patolojilerin teşhisinde dijital radyografiler, bilgisayarlı tomografi (CT) ve manyetik rezonans görüntülemeden (MRI) sonra cone beam bilgisayarlı tomografiler (CBCT) kullanılmaya başlanmıştır. Periapikal radyografiler ile diş ve periapikal kemik yapıları mesio-distal yönde net bir şekilde görülmekle birlikte, bukko-lingual yönde sıklıkla yetersiz kalmaktadır. Üç boyutlu görüntüler, geleneksel yöntemle alınan görüntülerdeki süperpozisyon problemini ortadan kaldırmaktadır. ${ }^{21,22}$

Dento-alveoler travmanın yaygın komplikasyonları arasında pulpa nekrozu, pulpa kanal obliterasyonu, periapikal patolojiler, kök rezorpsiyonu ve hatta kök rezorpsiyonuna bağı diş kaybı bulunmaktadır. CBCT ile özellikle dış kök rezorpsiyonun yeri ve yaygınlığı saptanarak tedavinin ne kadar kompleks olabileceği ve tedavi sonucu değerlendirilebilmektedir. ${ }^{21,23}$

\section{KOMPLİKASYONLAR}

\section{-Enfeksiyona bağlı kök rezorpsiyonu}

Enfeksiyona bağlı kök rezorpsiyonu asemptomatik bir lezyon olması sebebiyle teşhisi ve tedavisi zor olan patolojik bir durumdur. Radyografide karakteristik olarak kök yüzeyinde kase şeklinde radyolusent lezyonlar olarak görülmekte, kök kanal boşluğunda enfekte nekrotik doku varlığı ile ilişkili olarak gelişmektedir.

Tedavisinde kök kanalındaki enfekte nekrotik pulpa dokusu kanal boşluğundan uzaklaştırılarak rezorptif süreç durdurulmaya, hasar gören kök yüzeyinin sert doku ile tamiri ile iyileşmesini sağlamak için uygun bir ortam oluşturulmaya çalışılmaktadır. Rezorpsiyon ne kadar erken teşhis edilip ve tedavisi yapılır ise etkilenen dişin prognozu o kadar iyi olmaktadır. Rezorpsiyonun teşhis edilememesi ise diş kaybına yol açabilmektedir. ${ }^{1}$ Majorana ve ark., lüksasyon travmaları sonrası kök rezorpsiyonu oranının (\%4.7) replantasyon olgularına göre (\%49.3) düşük 
olduğunu, enfeksiyona bağlı kök rezorpsiyonu olgularının yarısında bu sürecin geçici nitelikte olup spontan iyileşme gösterdiğini, diğer yarısında ise ilerleyici karakterde olup uygun zamanda yapılan endodontik tedaviler ile engellenebildiğini bildirmişlerdir. ${ }^{24}$ Hermann ve ark. ${ }^{25}$ sarsılma ve sulbüksasyon yaralanmalarında periodontal komplikasyon gelişme riskinin düşük olduğunu, enfeksiyonla ilişkili kök rezorpsiyonunun sadece kuron kırığının eşlik ettiği sublüksasyon travmalarında görüldüğünü bildirilmişlerdir. Hecova ve ark. ${ }^{26} \mathbf{i}$ se çalışmalarında sarsılma ve sublüksasyon yaralanmalarında enflamatuar kök rezorpsiyonu ile karşılaşmamışlardır.

-Pulpa kanal obliterasyonu sonrası pulpa nekrozu

Pulpa kanalı obliterasyonu (PKO), kalsifik metamorfoz olarak da bilinen bir travma sekelidir. Sıklıkla sarsılma ve sublüksasyon yaralanmalarından sonra gelişmektedir. ${ }^{27}$ Bu durumda pulpanın travmaya yanıtı kök kanal boşluğunda sert doku depozisyonu ile olmaktadır. Klinik olarak en erken 3. ayda saptanabilmektedir. Etkilenen dişte dentin kalınlığı arttıkça translusenslik azalmakta ve komşu dişlere göre daha koyu bir renk almaktadır. Kuronda sarı veya gri renk değişimi görülebilmektedir. PKO ile birlikte pulpa nekrozu meydana gelen dişlerde gri renk değişimi gözlenmektedir. ${ }^{28}$

Yayınlanan bir çalışmada radyografik görüntüler üzerinden periapikal bölge bir periapikal indeks (PAI) ile değerlendirilmiş; perküsyon hassasiyeti bulunan, EPT'ye yanit vermeyen ve PAI'nin 3'ten büyük olduğu PKO'lu dişlerde endodontik tedaviye başlanması gerektiği bildirilmiştir. ${ }^{29}$

\section{SONUÇ}

Travma gören dişlerin endodontik tedavisi üzerinde birçok makale ve derleme bulunmasına rağmen halen tam olarak anlaşılamamıştır. Bu dişlerin endodontik tedavisi üzerine yapılan bilimsel çalışmaların sonucunda tedavi protokolünde kesin bir protokole ulaşılamamıştır.

Travma sonrası radyografide görülen periradiküler enflamatuar değişiklikler pulpa boşluğundaki bakteri varlığıyla ilişkili olmaktadır. Yapılan çalışmalarda periapikal radyolusensliği bulunan apeksi kapalı, lüksasyon travması görmüş dişlerde sınırlı sayıdaki olguda spontan iyileşme ve pulpa kanal obliterasyonu görülmektedir. Minimal invaziv tedavi yöntemlerinin öneminin arttığı günümüzde TAB takibi, travma gören dişlerde farklı bir tedavi yaklaşımı olarak değerlendirilmektedir.

\section{KAYNAKLAR}

1. Andreasen JO, Andreasen FM Andersson L. Luxation Injuries of Permanent Teeth: General Findings. In: Textbook and Color Atlas of Traumatic Injuries to the Teeth. 4th ed. Blackwell; Munksgaard: 2007. p.374-82.

2. Andreasen FM, Pedersen VM. Prognosis of luxated permanent teeth-the development of pulp necrosis. Dent Traumatol 1985;1:207-20.

3. Robertson A, Andreasen FM, Andreasen JO, Noren JG. Long-term prognosis of crownfractured permanent incisors. The effect of stage of root development and associated luxation injury. Int J Paediatr Dent 2000;10:191-9.

4. Andreasen JO, Andreasen FM, Bakland LK, Flores MT. Diagnosis of Pulp Healing Complications. In: Traumatic Dental Injuries: A Manual. 2nd ed. Blackwell; Munksgaard: 2003. p.22.

5. Andreasen FM. Transient apical breakdown and its relation to color and sensibility changes after luxation injuries to teeth. Endod Dent Traumatol 1986;2:9-19.

6. Boyd KS. Transient apical breakdown following subluxation injury: a case report. Endod Dent Traumatol 1995;11:37-40.

7. Cohenca N, Karni S, Rotstein I. Transient apical breakdown following tooth luxation. Dent Traumatol 2003;19:289-91.

8. Tsukiboshi M. Transient Apical Breakdown. In: Treatment Planning for Traumatized Teeth. Ed. Bryn Grisham. 2nd ed. Quintessence Publishing; Hanover Park, IL: 2012. p.143.

9. Skoglund A, Tronstad L, Wallenius K. A microangiographic study of vascular changes in replanted and autotransplanted teeth of young dogs. Oral Surg Oral Med Oral Pathol 1978;45:17-28.

10. Skoglund A, Tronstad L. Pulpal changes in replanted and autotransplanted immature teeth of dogs. J Endod 1981;7:309-16.

11. Kristerson L, Andreasen JO. Influence of root development on periodontal and pulpal healing after replantation of incisors in monkeys. Int J Oral Surg 1984;13:313-23. 
12. Kobayashi K, Kotani Y, Takahashi T, Nakamura Y, Suzuki E, Ide Y, Shin K. Transient apical breakdown in subluxated maxillary incisor. J Meikai Dent Med 2013;43:63-8.

13. Andreasen FM. Pulpal healing after luxation injuries and root fracture in the permanent dentition. Endod Dent Traumatol 1989;5:111-31.

14. Tsukiboshi M. Optimal use of photography, radiography and micro computed tomography scanning in the management of traumatized teeth. Endodontic Topics 2006;14:4-19.

15. Andreasen JO, Andreasen FM, Mejare I, Cvek M. Healing of 400 intra-alveolar root fractures. 1. Effect of pre-injury and injury factors such as sex, age, stage of root development, fracture type, location of fracture and severity of dislocation. Dent Traumatol 2004;20: 192-202.

16. Andreasen JO, Andreasen FM, Mejare I, Cvek M. Healing of 400 intra-alveolar root fractures. 1. Effect of treatment factors such as treatment delay, repositioning, splinting type and period and antibiotics. Dent Traumatol 2004;20:203-11.

17. Cvek M, Mejare I, Andreasen JO. Healing and prognosis of teeth with intra-alveolar fractures involving the cervical part of the root. Dent Traumatol 2002; 18:57-65.

18. Hecova H, Tzigkounakis V, Merglova V, Netolicky J. A retrospective study of 889 injured permanent teeth. Dent Traumatol 2010;26:46675.

19. Andreasen FM, Andreasen JO. Resorption and mineralization processes following root fracture of permanent incisors. Endod Dent Traumatol 1988;4:202-14.

20. Malmgren $B$, Hübei S. Transient discoloration of the coronal fragment in intra-alveolar root fractures. Dent Traumatol 2012;28:200-4.

21. Cohenca N, Simon JH, Mathur A, Malfaz JM. Clinical indicatios for digital imaging in dentoalveolar trauma. Part 2: root resorption. Dent Traumatol 2007;23:105-13.

22. Çakur B, Sümbüllü MA, Durna $D$, Çanakçı CF. Dental volumetric computed tomography in the radiological detection of dento-alveolar fracture. J Dent Fac Atatürk Uni 2012;22:57-60.

23. Durack C, Patel S, Davies J, Wilson R, Mannocci F. Diagnostic accuracy of small volume cone beam computed tomography and intraoral periapical radiography for the detection of simulated external inflammatory root resorption. Int Endod J 2011;44:136-47.

24. Majorana A, Bardellini E, Conti G, Keller E, Pasini S. Root resorption in dental trauma: 45 cases followed for 5 years. Dent Traumatol 2003;19:262-5.

25. Hermann NV, Lauridsen E, Ahrensburg SS, Gerds TA, Andreasen JO. Periodontal healing complications following concussion and subluxation injuries in the permanent dentition: a longitudinal cohort study. Dent Traumatol 2012;28:386-93.

26. Hecova H, Tzigkounakis V, Merglova V, Netolicky J. A retrospective study of 889 injured permanent teeth. Dent Traumatol 2010;26:46675.

27. DiAngelis $A J$, Andreasen JO, Ebeleseder $K A$, Kenny DJ, Trope M, Sigurdsson A, Andersson L, Bourguignon $C$, Flores $M T$, Hicks $M L$, Lenzi $A R$, Malmgren B, Moule AJ, Pohi $Y$, Tsukiboshi $M$. Internetional Association of Dental Traumatology guidelines for the management of traumatic dental injuries: 1. Fractures and luxations of permanent teeth. Dent Traumatol 2012;28:2-12.

28. Robertson A, Andreasen FM, Bergenholtz G, Andreasen JO, Noren JG. Incidence of pulp necrosis subsequent to pulp canal obliteration from trauma of permanent incisors. JOE 1996;22:557-60.

29. Oginni AO, Adekoya-Sofowora CA, Kolawole KA. Evaluation of radiographs, clinical signs and symptoms associated with pulp canal obliteration: an aid to treatment decision. Dent Traumatol 2009;25:620-5.

\section{Yazışma Adresi:}

Dt. Yelda Kasımoğlu

İstanbul Üniversitesi Diş hekimliği Fakültesi, Pedodonti Anabilim Dalı, 34093, Çapa, İstanbul Tel: 0212414 2020/30283

Fax: 02125310515

e-posta: yeldakasimoglu@gmail.com 